\title{
Reconstrução de ponte nasal com tela de titânio após exérese tumoral em um cão
}

\author{
Nasal bridge reconstruction with titanium mesh after tumor excision in a dog
}

\author{
Renan Marcel Krüger ${ }^{*}$ Lucas Marques Colomé $^{I I}$ Daniel Curvello de Mendonça Müller ${ }^{\mathrm{III}}$ \\ Cristiano Gomes ${ }^{\mathrm{I}}$ Anne Santos do Amaral ${ }^{\mathrm{IV}}$
}

\section{- NOTA -}

\section{RESUMO}

\begin{abstract}
O presente trabalho relata o uso de tela de titânio como alternativa para reconstrução do defeito ósseo criado pela ressecção agressiva de carcinoma de células escamosas da ponte nasal em cão. Após o tratamento quimioterápico com 5-fluorouracil tópico e sistêmico associado à piroxicam para a redução da massa tumoral, foi realizada a ressecção cirúrgica da região comprometida e reparo do defeito ósseo com tela de titânio e posterior recobrimento com retalho músculo-cutâneo unipediculado de avanço. A principal complicação no período pós-operatório foi a formação de enfisema subcutâneo, controlado em três dias com drenagem do ar e aplicação de bandagens compressivas. $O$ animal permaneceu sem sinais de recidiva por oito meses. No décimo mês pós-operatório, o paciente apresentou miíase no local da recidiva e a proprietária optou pela eutanásia. Com esse caso, foi possivel concluir que a tela de titânio foi um material adequado para a reconstrução da ponte nasal, tendo como principal complicação a ocorrência de enfisema subcutâneo.
\end{abstract}

Palavras-chave: rinoplastia, implante, carcinoma de células escamosas.

\section{ABSTRACT}

This paper describes the use of titanium mesh as an alternative for reconstruction of bone defect created by resection of aggressive squamous cell carcinoma of the nasal bridge in a dog. After chemotherapy with topic and systemic 5-fluorouracil associated with piroxicam for the tumor mass reduction, it was performed a surgical resection of the affected region, repair of bone defects with titanium mesh and subsequent closing of the wound with musculocutaneous single pedicle advancement flap. The main complication in the postoperative period was the formation of subcutaneous emphysema, which was controlled in three days with air drainage and application of compression bandages. The animal remained without signs of recurrence for eight months. In the tenth month postoperatively, the patient presented myiasis in local recurrence and the owner opted for euthanasia. In this case, it was possible to conclude that titanium mesh was a suitable material for the reconstruction of the nasal bridge, having as main complication the occurrence of subcutaneous emphysema.

Key words: rhinoplasty, implant, squamous cell carcinoma.

Tumores de pele e subcutâneo são os mais comuns dos cães, compreendendo cerca de um terço do total das massas neoplásicas dessa espécie. Em cães, a prevalência de carcinoma de células escamosas (CCE) é variável, sendo responsável por 5 a $7 \%$ dos tumores cutâneos (SOUZA et al., 2006; VAIL \& WITHROW, 2007). Os tumores de cavidade nasal representam $1 \%$ do total de neoplasmas dos cães, dos quais dois terços são carcinomas, incluído o CCE (TUREK \& LANA, 2007).

Segundo LASCELLES et al. (2000), o CCE pode se apresentar como uma lesão proliferativa ou ulcerativa. Podem ser localmente muito invasivos, porém as metástases raramente ocorrem (TUREK \& LANA, 2007).

'Programa de Pós-graduação em Medicina Veterinária, Universidade Federal de Santa Maria (UFSM), 97105-900, Santa Maria, RS, Brasil. E-mail: renankruger@yahoo.com.br. *Autor para correspondência.

"Faculdade de Medicina Veterinária e Agronomia, Universidade de Passo Fundo (UPF), Passo Fundo, RS, Brasil.

IIIDepartamento de Estudos Agrários, Universidade Regional do Noroeste do Estado do Rio Grande do Sul (UNIJUÍ), Ijuí, RS, Brasil. ${ }^{\text {IV }}$ Departamento de Clínica de Pequenos Animais, UFSM, Santa Maria, RS, Brasil. 
O tratamento de escolha envolve a ressecção agressiva do tumor (MACDONALD et al., 2008). Materiais como os implantes de polietileno, metilmetacrilato, silicone, supramide, proplast, politetrafluoretileno, dacron, gore-Tex, os homoenxertos e autoenxertos de cartilagem e ossos têm sido usados com sucesso como enxertos para a correção do dorso nasal em rinoplastias (PATROCÍNIO \& PATROCÍNIO, 2001; SANTOS JÚNIOR et al., 2008).

O objetivo deste trabalho é relatar o uso de tela de titânio como alternativa eficaz para a reconstrução do defeito ósseo criado pela ressecção ampla de CCE da ponte nasal em cão.

Foi atendido um cão sem raça definida, de 9 anos de idade e $10 \mathrm{~kg}$ de massa corporal, com lesão proliferativa e hemorrágica de cerca de $4 \mathrm{~cm}$ de diâmetro na região da ponte nasal. Apresentava epistaxe, espirros, estertores inspiratórios, anorexia e apatia. Segundo a proprietária, a lesão, com dez meses de evolução, iniciou-se como área eritematosa, tornandose ulcerada em menos de dois meses. Uma punção não aspirativa por agulha fina possibilitou o diagnóstico citológico de carcinoma de células escamosas, posteriormente confirmado na histopatologia. Radiografias da face revelaram destruição óssea na maior parte da ponte nasal e dos cornetos. Pelo exame radiográfico do tórax não se evidenciou imagens compatíveis com metástases pulmonares. O hemograma e as provas bioquímicas para avaliação das funções renal e hepática não constataram qualquer alteração.

Iniciou-se o tratamento clínico com antibioticoterapia sistêmica para combate à sinusite e aplicação tópica de 5-fluorouracila (5-FU) creme ${ }^{\text {a }}$ 5\% BID, administrações semanais de 5-FU injetável ${ }^{\mathrm{b}}$ pela via intravenosa $\left(200 \mathrm{mg} \mathrm{m}^{-2}\right)$ e piroxicam ${ }^{\mathrm{c}}\left(0,03 \mathrm{mg} \mathrm{kg}^{-1}\right.$, VO) SID, na tentativa de reduzir a massa para posterior exérese cirúrgica, que foi realizada após 30 dias.

O paciente, sob anestesia geral, foi posicionado em decúbito esternal (Figura 1A), com a mandíbula apoiada sobre compressas. Após anti-sepsia e colocação dos campos cirúrgicos, fez-se a incisão cutânea elíptica (margem de segurança de $0,5 \mathrm{~cm}$ ), removendo-se a massa tumoral. Foi criado um defeito ósseo retangular desde a porção mais caudal da ponte nasal até sua porção média com uma fresa de disco ${ }^{\mathrm{d}}$ $(12 \times 28 / 16 \mathrm{~mm})$ acoplado a um motor de baixa rotação ${ }^{\mathrm{e}}$, removendo-se as estruturas ósseas correspondentes e os cornetos nasais (Figura 1B). Durante a secção, foi instilada solução salina isotônica na região. Drenouse, curetou-se e lavou-se exaustivamente a região.

Procedeu-se então ao processo de reconstrução da ponte nasal. Uma tela de titânio $\mathrm{CP}$ (Commercially Pure), grau 2, com 0,3mm de espessura ${ }^{f}$
$(5 \times 5 \mathrm{~cm})$ foi adaptada à ferida, preenchendo o defeito ósseo. A tela foi fixada com dois parafusos de titânio CP, grau 4, com 1,5mm de diâmetro, em cada extremidade, propiciando sustentação para a patência das vias aéreas superiores (Figura 1C). Para o recobrimento, criou-se um retalho músculo-cutâneo unipediculado de deslizamento a partir da região parietal (Figura 1D), sendo a camada muscular suturada à tela e ao tecido subcutâneo adjacente à ferida com fio de ácido poliglicólico, utilizando-se sutura interrompida simples em padrão walking suture, transpassando os orifícios e promovendo contato entre o tecido do retalho e o implante metálico enquanto este era direcionado rostralmente para o total recobrimento da ferida. A pele foi suturada com fio de náilon monofilamentar em sutura interrompida simples (Figura 1E).

No pós-operatório, administrou-se piroxicam $\left(0,03 \mathrm{mg} \mathrm{kg}^{-1}\right.$, VO) SID, dipirona ${ }^{\mathrm{g}}\left(25 \mathrm{mg} \mathrm{kg}^{-1}\right.$, IM) TID e cloridrato de $\operatorname{tramadol}^{\mathrm{h}}\left(5 \mathrm{mg} \mathrm{kg}^{-1}\right.$, IM) TID, durante cinco dias. Foi também prescrito enrofloxacino (5mg kg-1, $\mathrm{VO}$ ) BID durante 14 dias, pois se evidenciou a persistência de sinusite durante a invasão do seio maxilar direito pela serra circular na criação do defeito ósseo. Exames radiográficos foram realizados para o controle do posicionamento da tela e evolução cicatricial. Após 10 dias, os pontos cutâneos foram removidos e o animal teve alta hospitalar, com resultado estético satisfatório. Espirros esporádicos permaneceram durante todo o período após o procedimento.

Os sinais mais comuns em cães com tumores nasais são: epistaxe, espirros frequentes e ulceração ou aumento de volume nasal (ROGERS et al., 1995; LASCELLES et al., 2000). Além desses, o cão deste relato ainda apresentava estertores inspiratórios e corrimento nasal sero-sanguinolento, bem como contaminação secundária e crostas aderidas em toda a região.

Como o CCE responde fracamente à radioterapia ou quimioterapia isolada, o tratamento quase sempre inclui a ressecção cirúrgica (MACDONALD et al., 2008). Neste caso, optou-se por realizar quimioterapia com 5-FU tópico e sistêmico e piroxicam, pela facilidade da aplicação, disponibilidade e segurança durante a manipulação. Comparado a outras drogas, o 5-FU é considerado de baixo custo e bem tolerado pelos cães (CHUN et al., 2007). Piroxicam, um anti-inflamatório não-esteroidal (AINE), é indicado para o tratamento de CCE devido à sua ação sobre os queratinócitos neoplásicos, os quais apresentam expressão aumentada de ciclooxigenase-2 e prostaglandina-E2, em comparação às células normais (PRONOVOST et al., 2004; DE VOS et al., 2005). 


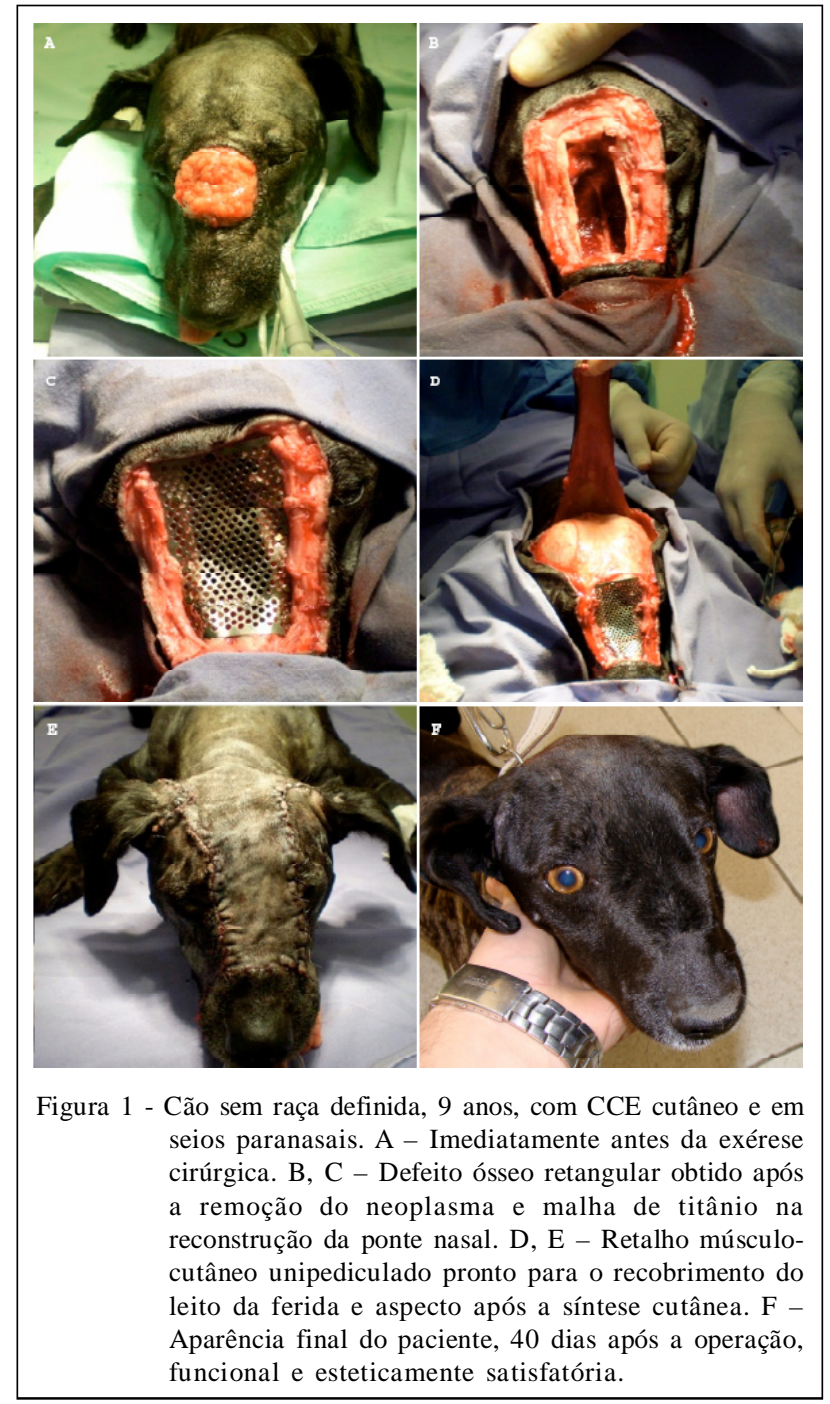

Não foram observados efeitos colaterais no paciente ou alterações significativas da série eritróide e contagem leucocitária nos hemogramas realizados semanalmente durante todo o período do tratamento quimioterápico. Após trinta dias do início da terapia, a área ulcerada tornou-se menos cruenta e uma redução de aproximadamente $10 \%$ da área externa foi obtida, optando-se pela ressecção cirúrgica da região comprometida.

Uma grande vantagem observada na utilização da tela de titânio foi a facilidade de moldagem na região a ser fixada. Além disso, somam-se a facilidade de esterilização, a biocompatibilidade e a estabilidade oferecida às estruturas após a aplicação do implante (GREER \& PEARSON, 1998). A grande falha de tecido resultante da extirpação do tumor foi preenchida por um retalho de avanço unipediculado, removido da porção parietal do crânio.
Uma complicação da técnica utilizada foi a ocorrência de moderado enfisema subcutâneo, decorrente da comunicação propiciada pelos orifícios da tela metálica entre as vias aéreas e o espaço subcutâneo do retalho. NELSON (1998) sugeriu a criação de uma rinostomia temporária na extremidade sinusal da ponte nasal como forma de redução do enfisema subcutâneo, além da possibilidade de instilação de medicamentos por essa via. Neste caso, optou-se pela realização de bandagens compressivas em todo o corpo do animal, inclusive sobre o enxerto. Esse artifício controlou o extravasamento do ar e ao terceiro dia pós-operatório o enfisema já havia desaparecido.

Oito meses após o procedimento cirúrgico, iniciaram-se sinais de recidiva, sendo observado um pequeno ponto hemorrágico próximo à rima medial do 
olho direito e espirros mais frequentes, algumas vezes com estrias de sangue. Aos 10 meses, uma ferida hemorrágica com miíase foi observada no mesmo local, demonstrando o cão evidente desconforto ao respirar. A proprietária optou pela eutanásia do paciente e a necropsia não foi autorizada.

Com este caso, é possível concluir que a tela de titânio foi um material adequado para a reconstrução do plano nasal, tendo como principal complicação a ocorrência de enfisema subcutâneo, quando associado a longos retalhos pediculados.

\section{FONTES DE AQUISIÇÃO}

a - Efurix ${ }^{\circledR}$ creme. Laboratório Valeant. São Paulo - SP.

b - Fluoro-Uracil® injetável. Laboratório Valeant. São Paulo SP.

c - Inflamene ${ }^{\circledR}$ gotas. Laboratório Farmalab. São Paulo - SP.

d - Synthes Indústria e Comércio. Rio Claro - SP.

e - Motor de Suspensão Mini®. Beltec Indústria e Comércio de Equipamentos Odontológico. Araraquara - SP.

f - Implax® Indústria e Comércio de Materiais Veterinários. Porto Alegre - RS.

g - Analgex V®. Laboratório Agener União. São Paulo - SP.

h - Tramadon®. Laboratório Cristália. São Paulo - SP.

i - Enrofloxacina. Laboratório Tortuga. São Paulo - SP.

\section{REFERÊNCIAS}

CHUN, R. et al. Cancer chemotherapy. In: WITHROW, S.J.; VAIL, D.M. Withrow and MacEwen's small animal clinical oncology. 4.ed. Saint Louis: Saunders, 2007. Cap.22, p.163-192.

DE VOS, J.P. et al. Piroxicam and carboplatin as a combination of treatment of canine oral non-tonsillar squamous cell carcinoma. Vet Comparat Oncol, v.3, n.1, p.16-24, 2005. Disponível em: <http://web.ebscohost.com/ehost/pdfviewer/ pdfviewer?vid=1\&hid=104\&sid=5ead2 1b2-6602 -4 d06-8f794180e49be97f\%40sessionmgr113. Acesso em: 3 jul. 2010. doi: $10.1111 / \mathrm{j} .1476-5810.2005 .00065 . x>$.

GREER, R.T.; PEARSON, P.T. Biomateriais. In: SLATTER, D. Manual de cirurgia de pequenos animais. São Paulo: Manole, 1998. Cap. 9, p.133-142.
LASCELLES B.D.X. et al. Squamous cell carcinoma of the nasal planum in 17 dogs. Vet Record, v.147, n.17, p.473-476, 2000 .

MACDONALD, V. et al. Tumors of the skin and subcutis. In: ARGYLE, D.J. et al. Decision making in small animal oncology. Ames: Wiley-Blackwell, 2008. Cap.6, p.129-145.

NELSON, A.W. Sistema respiratório superior. In: SLATTER, D. Manual de cirurgia de pequenos animais. São Paulo: Manole, 1998. Cap.52, p.884-935.

PATROCÍNIO, L.G; PATROCÍNIO, J.A. Uso de enxertos em rinoplastia. Arq Intern Otorrinolaringol, v.5, n.1, p.21$25,2001$.

PRONOVOST, N. et al. Expression and regulation of cyclooxygenase-2 in normal and neoplastic canine keratinocytes. Vet Comparat Oncol, v.2, n.4, p.222-233, 2004. Disponível em: <http://web.ebscohost.com/ehost/ pdfviewer/pdfviewer?vid $=6 \&$ hid $=104 \&$ sid $=\mathrm{d} 3 \mathrm{f} 9 \mathrm{~b} 4 \mathrm{a} 3-982 \mathrm{~b}-$ 4d08-a9a9-d2eab8e69f2a\%40sessionmgr112>. Acesso em: 3 jul. 2010 . doi: 10.1111/j.1476-5810.2004.00055.x.

ROGERS, K.S. et al. Squamous cell carcinoma of the canine nasal planum: eight cases (1988-1994). J Amer Anim Hosp Assoc, v.31, n.5, p.373-378, 1995.

SANTOS JÚNIOR, E.B. et al. Rinoplastia experimental com enxerto autógeno de costela em cães. Arq Bras Med Vet Zootec, v.60, n.2, p.346-352, 2008. Disponível em: <http:// www.scielo.br/scielo.php?script $=$ sci_arttext $\&$ pid $=S 0102$ 09352008000200011\&lng=pt\&nrm=iso >. Acesso em: 3 jul. 2010. doi: 10.1590/S0102-09352008000200011.

SOUZA. T.M. et al. Estudo retrospectivo de 761 tumores cutâneos em cães. Ciênc Rural, v.36, n.2, p.555-560, 2006. Disponível em: $<$ http://www.scielo.br/scielo.php?script=sci_arttext\&pid=S0103$84782006000200030 \& \operatorname{lng}=\mathrm{en} \& \mathrm{nrm}=\mathrm{iso} \& \mathrm{tlng}=\mathrm{pt}>$. Acesso em: 3 jul. 2010. doi: 10.1590/S0103-84782006000200030.

TUREK, M.M.; LANA, S.E. Canine nasosinal tumors. In: WITHROW, S.J.; VAIL, D.M. Withrow and MacEwen's small animal clinical oncology. 4.ed. Saint Louis: Saunders, 2007. Cap.22, sec.D, p.525-539.

VAIL, D.M; WITHROW, S.J. Tumors of the skin and subcutaneous tissues. In: WITHROW, S.J.; VAIL, D.M. Withrow and MacEwen's small animal clinical oncology. 4.ed. Saint Louis: Saunders, 2007. Cap.18, p.375-401. 